\title{
Single and binary adsorption of sulfonamide antibiotics onto iron-modified clay: linear and nonlinear isotherms, kinetics, thermodynamics, and mechanistic studies
}

\author{
Victor O. Shikuku ${ }^{1,2} \cdot$ Renato Zanella $^{2} \cdot$ Chrispin O. Kowenje $^{1} \cdot$ Filipe F. Donato $^{2} \cdot$ Nelson M. G. Bandeira ${ }^{2}$. \\ Osmar D. Prestes ${ }^{2}$
}

Received: 6 March 2018 / Accepted: 13 September 2018 / Published online: 24 September 2018

(c) The Author(s) 2018

\begin{abstract}
Iron-modified raw kaolinite clay (Fe-MC) was synthesized by co-precipitation method, characterized, and then applied as a low-cost adsorbent to sequester sulfachloropyridazine (SCP) and sulfadimethoxine (SDM), emergent water contaminants, from aqueous media by batch equilibration at circumneutral $\mathrm{pH}$. The adsorption rate was kinetically described by the pseudosecond-order model. Equilibrium monocomponent sorption data were fitted to three two-parameter linear and nonlinear isotherm models. The data were best described by Temkin and Langmuir nonlinear equations. Linearization of adsorption isotherms is demonstrated to be an unsuitable analytical tool for predicting adsorption isotherms. The Langmuir monolayer maximum adsorption capacities were 4.561 and $1.789 \mathrm{mg} / \mathrm{g}$ for SCP and SDM, respectively. The binary adsorption study showed an antagonistic adsorption process of $\mathrm{SCP}\left(R_{q, \mathrm{SCP}}=0.625\right)$ in the presence of $\mathrm{SDM}\left(R_{q, \mathrm{SDM}}=1.032\right)$. The thermodynamic parameters, namely enthalpy $(\Delta \mathrm{H})$, Gibbs free energy $(\Delta \mathrm{G})$, entropy $(\Delta \mathrm{S})$, Arrhenius activation energy $\left(\Delta \mathrm{E}_{\mathrm{a}}\right)$, and sticking probability $\left(S^{*}\right)$, indicated that the processes are spontaneous, exothermic, and physical in nature. The adsorption process was attributed to hydrogen bonding and negative charge-assisted $\mathrm{H}$-bonding (CAHB). Using the Langmuir isotherm, the amount of Fe-MC required for a given volume of effluent of known contaminant concentration could be predicted.
\end{abstract}

\section{Graphical abstract}

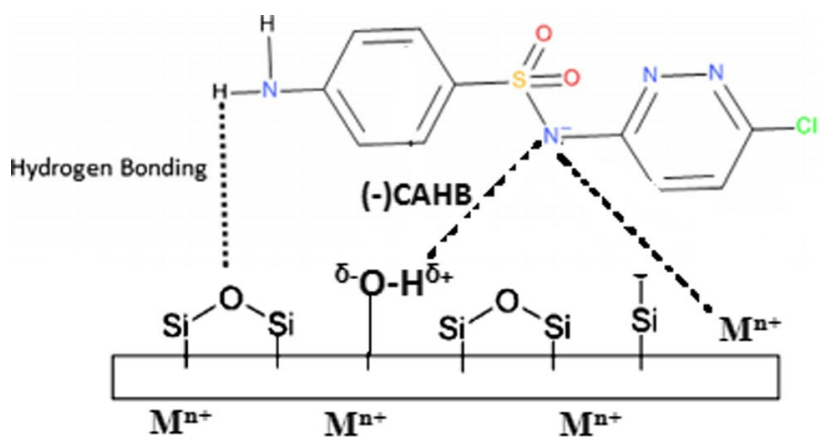

Keywords Iron oxide $\cdot$ Kaolinite $\cdot$ Adsorption $\cdot$ Sulfonamides $\cdot$ CAHB

Victor O. Shikuku

odhiambo_shik@yahoo.com

Maseno University, P.O. Box 333, Maseno 40105, Kenya

2 Laboratory of Pesticide Residue Analysis (LARP), Chemistry Department, Federal University of Santa Maria, Santa Maria, RS 97105-900, Brazil

\section{Introduction}

Both human population and industrial growth generate increasing constraint on earth's freshwater supply resources (Kolpin et al. 2002). Consequently, there has been a growing concern over the residue levels of several classes of chemical 
compounds in water sources as generated from veterinary-, industry, and other agriculture-related activities (Ma et al. 2015; Zhang et al. 2014). In recent years, pharmaceutical compounds have been frequently detected in natural water resources, treated wastewaters, and drinking potable waters (Primel et al. 2012). Sulfonamides; bacteriostatic antibiotics used against gram-positive and gram-negative organisms, have been frequently detected in effluents from wastewater treatment facilities (Kimosop et al. 2016; Ngumba et al. 2016), indicating their resistance to conventional water treatment approaches and the need for continued search for sustainable and efficient water treatment alternatives. Exposure to non-target organisms for sulfonamides has been associated with stomatitis, hemolysis, hepatotoxicity, and renal toxicity (Baran et al. 2011; Bialk-bielinska et al. 2011). Suitable adsorbents for removal of these polar compounds from water bodies still need to be evaluated.

Since antiquity, clays have been used in ceramic materials and for water treatment. Of particular interest is application of clays in wastewater treatment due to their relatively high adsorption capacities, abundance in nature, inexpensiveness, and eco-friendly properties. In recent years, pillared interlayed clays have received considerable attention in adsorption studies of various pollutants (Mehta et al. 2015). Pillarization is expected to increase the materials' porosity, surface area, and thermal stability imbuing the composite with higher adsorptive capabilities (Boruah et al. 2015; Tireli et al. 2014).

Additionally, iron oxide-modified clays have attracted increasing applications due to the low cost of iron and the synergistic combination of the magnetic properties of iron and the adsorptive features of the host material. Furthermore, intercalation of iron particles may increase the interlayer space, which promotes the penetration of the molecular adsorbates to the inner active sites within the clay structure (Tireli et al. 2014). However, the characteristics of the intercalated adsorbent and the mechanisms of the adsorbate-adsorbent interactions need to be fully understood for possible optimization.

In this study, raw clay modified with iron phase was fabricated by co-precipitation method (Salem et al. 2013). The chemically treated clay (Fe-MC) was subsequently used for sequestration of sulfonamides antimicrobial agents of varied physicochemical and structural properties, namely sulfachloropyridazine (SCP) and sulfadimethoxine (SDM), from aqueous media in single and binary solutions.

\section{Materials and methods}

\section{Preparation of adsorbent}

The raw clay material, from Bungoma town, Kenya, was crushed and homogenized for the adsorption experiments. The material was sieved through $220-\mu \mathrm{m}$ sieve for particle size uniformity. The adsorbent was then thrice washed in ultrapure water to remove impurities. Finally, the material (grey in color) was thermally dried to constant mass at $333 \mathrm{~K}$ with no further chemical modifications. The chemically treated clay (Fe-MC) was prepared as described by Salem et al. (2013). Briefly, $0.5 \mathrm{~g}$ of homogenized clay was mixed with $6.1 \mathrm{~g}$ of $\mathrm{FeCl}_{3} \cdot 6 \mathrm{H}_{2} \mathrm{O}$ and $4.2 \mathrm{~g}$ of $\mathrm{FeSO}_{4} \cdot 7 \mathrm{H}_{2} \mathrm{O}$, each of $99 \%$ purity, and then dissolved in $100 \mathrm{~mL}$ of deionized water. The $\mathrm{pH}$ of the mixture was adjusted to $10.0 \mathrm{using}$ $0.1 \mathrm{M} \mathrm{NaOH}$, and then the matrix was sonicated then agitated in a rotary shaker at $160 \mathrm{rpm}$ for $8 \mathrm{~h}$. Thereafter, $25 \mathrm{~mL}$ of the $6.5 \mathrm{M} \mathrm{NaOH}$ was slowly added and mixed for an hour with the above solution. The resulting black precipitate was washed with ultrapure water and finally heated in an oven at $373 \mathrm{~K}$ for $24 \mathrm{~h}$.

\section{Adsorbent characterization}

The specific surface areas of the adsorbents were calculated from the BET liquid nitrogen adsorption-desorption method conducted at $77 \mathrm{~K}$ by employing a Micromeritics apparatus (Quadrasorb Evo 4, Quantachome, USA). The infrared spectrum of the unmodified and treated clay samples were obtained via a ATR-FTIR spectrometer (Nicolet iS-5, USA) over the wavenumber range $4000-400 \mathrm{~cm}^{-1}$. The crystalline phases were determined using X-ray Brucker diffractometer (D8 Advance) with copper radiation $\left(K_{\alpha}=1.5406\right)$. The point of zero charge $\left(\mathrm{pH}_{\mathrm{pzc}}\right)$ was determined using the $\mathrm{pH}$ drift method (Hosseinzadeh and Mohammadi 2015).

\section{Sorption kinetics}

The batch tests were carried out in sealed 250-mL Erlenmeyer flasks with $0.1 \mathrm{~g}$ of adsorbent dispersed in $50 \mathrm{~mL}$ of $1 \mathrm{mg} \mathrm{L}^{-1}$ solution of SCP or SDM obtained by dissolution of $1000 \mathrm{mg} \mathrm{L}^{-1}$ stock solutions prepared from $99 \%$ pure standards. The sealed flasks were agitated at $200 \mathrm{rpm}$ for $6 \mathrm{~h}$ in a controlled temperature shaker at $303 \pm 1 \mathrm{~K}$. At predetermined time intervals $(10,20,30,40,60,120,180,240$, 300,360 and $420 \mathrm{~min}$ ), the residual pollutant in solution was determined. The effect of initial pollutant concentration $\left(1.0,1.25,1.50,1.75,2.0 \mathrm{mg} \mathrm{L}^{-1}\right)$ at $303 \pm 1 \mathrm{~K}$, and thermodynamic studies at 303,313 , and $323 \mathrm{~K}$ were evaluated, in triplicates, while holding other parameters constant (i.e., initial $\mathrm{pH}$ of $5.9 \pm 0.2$ and adsorbent dosage of $0.1 \mathrm{~g} / 50 \mathrm{~mL}$ ). 
$0.5 \mathrm{~mL}$ aliquots were collected from the flasks and sieved through $0.2-\mu \mathrm{m}$ syringe filters into glass vials for analysis of the residual SCP and SDM concentrations in the solution using HPLC-DAD Varian (Palo Alto, CA, USA) at $270 \mathrm{~nm}$. Control experiments showed undetectable amount of the analytes were adsorbed on the glass or other losses. The mobile phase was a mixture of water (1\% acetic acid) and acetonitrile $(90: 10 \mathrm{v} / \mathrm{v})$, with a flow rate of $1.0 \mathrm{~mL} \mathrm{~min}^{-1}$. The injection volume was $50 \mu \mathrm{L}$. The amount of solute adsorbed per unit mass of adsorbent $\left(q_{e}\right)$ was calculated using the mass balance equation:

$q_{e}=\frac{\left(C_{\mathrm{i}}-C_{\mathrm{e}}\right) V}{m}$

The percent removal efficiency was calculated according to the following equation:

$\operatorname{Removal}(\%)=\frac{\left(C_{\mathrm{i}}-C_{\mathrm{e}}\right)}{C_{\mathrm{i}}} \times 100$,

where $C_{\mathrm{i}}$ is the initial solute concentration, $C_{\mathrm{e}}$ the equilibrium solute concentration in the bulk solution $\left(\mathrm{mg} \mathrm{L}^{-1}\right), V$ is solution volume (L) and $m$ is adsorbent mass (g). Iron leaching from the adsorbent was monitored using atomic absorption spectrometer model AAS 6 Vario (Analytik Jena, Germany) with atomizer flame air/acetylene at $248 \mathrm{~nm}$. Table 1 lists some physicochemical properties of the antibiotics.

Table 1 Selected properties of SCP and SDM

\begin{tabular}{|c|c|c|}
\hline Properties & $\begin{array}{l}\text { Sulfachloro- } \\
\text { pyridazine } \\
(\mathrm{SCP})\end{array}$ & Sulfadimethoxine (SDM) \\
\hline Molecular formula & $\mathrm{C}_{10} \mathrm{H}_{9} \mathrm{~N}_{4} \mathrm{ClO}_{2} \mathrm{~S}$ & $\mathrm{C}_{12} \mathrm{H}_{14} \mathrm{~N}_{4} \mathrm{O}_{4} \mathrm{~S}$ \\
\hline $\begin{array}{l}\text { Molecular weight }(\mathrm{g} / \\
\text { mol) }\end{array}$ & 284.72 & 310.33 \\
\hline $\begin{array}{l}\text { Aqueous solubility } \\
(\mathrm{mg} / \mathrm{L})\end{array}$ & 8235 & 66.81 \\
\hline Dipolar moment Debye & 13.45 & 6.39 \\
\hline $\log \mathrm{K}_{\mathrm{ow}}$ & 0.31 & 1.17 \\
\hline $\mathrm{pK}_{\mathrm{a}}$ & 5.70 & 5.80 \\
\hline Structure & & \\
\hline
\end{tabular}

Adopted from Huang et al. (2015)
Table 2 Adsorbent properties

\begin{tabular}{lcc}
\hline & Raw clay & Fe-MC \\
\hline Pore radius $(\mathrm{nm})$ & 3.73 & 4.26 \\
Pore volume $\left(\mathrm{cm}^{3} / \mathrm{g}\right)$ & 0.05 & 0.05 \\
$\mathrm{BET}$ surface $\operatorname{area}\left(\mathrm{m}^{2} / \mathrm{g}\right)$ & 10.30 & 10.26 \\
$\mathrm{pH}_{\mathrm{pzc}}$ & 6.1 & 6.2 \\
$\mathrm{Si} / \mathrm{Al}$ ratio & 2.29 & 2.77 \\
\hline
\end{tabular}

\section{Results and discussion}

\section{BET surface area and pore characteristics}

The textural characteristics (Table 2) indicate no change in the Brunauer-Emmett-Teller (BET) specific surface area of the Fe-MC relative to the raw clay showing minimal blockage of the raw clay pores by the iron oxide particles. The pore volume data calculations are consistent with this conclusion. These BET results indicate that a change in chemical composition does not necessarily affect textural characteristics. Any changes in reactivity are therefore attributed to dispersion of iron oxide particles and not textural properties.

\section{FTIR analysis}

Apart from XRD, literature affirms FTIR spectroscopy as a magnificent tool for distinguishing and quantifying the different magnetic iron oxides, namely magnetite $\left(\mathrm{Fe}_{3} \mathrm{O}_{4}\right)$ and magnetite $\left(\gamma-\mathrm{Fe}_{2} \mathrm{O}_{3}\right)$ (Gonçalves et al. 2013). The structural features and functional groups present are displayed in the FTIR plot (Fig. 1). Generally, there was decrease in intensities for all the bands in the Fe-MC relative to those

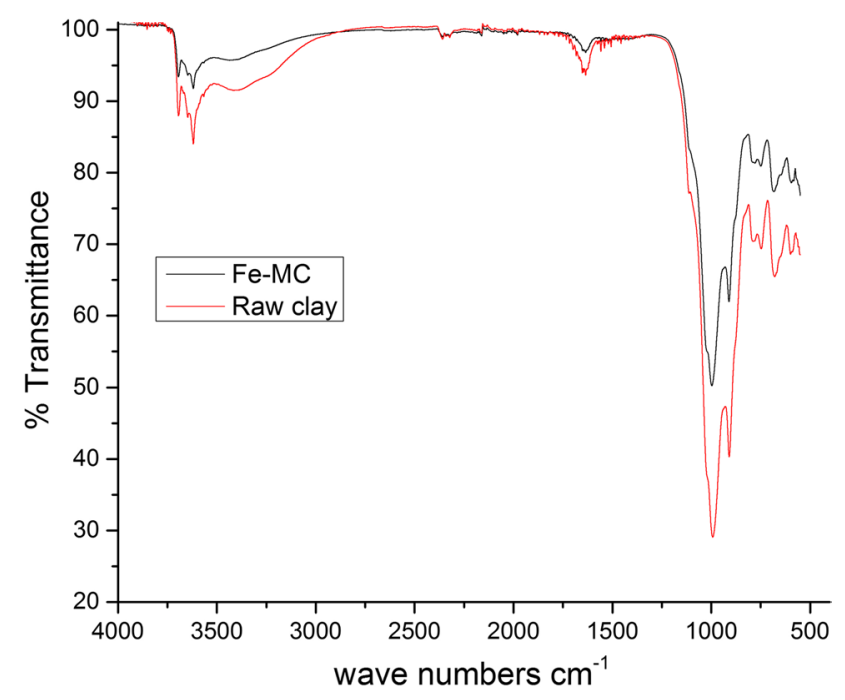

Fig. 1 FTIR spectrum for the iron-modified clay (Fe-MC) 
in raw clay with no observable new peak formation. The absorption band at $3694 \mathrm{~cm}^{-1}$ corresponds to the structural interlayer surface - $\mathrm{OH}$ stretching vibration, while a corresponding prominent band at $3619 \mathrm{~cm}^{-1}$ indicate the existence of outer $-\mathrm{OH}$ groups probably from surface adsorbed and interlayer water (Namduri and Nasrazadani 2008). The absorption band at $910 \mathrm{~cm}^{-1}$ was assigned to an -OH deformation vibration at the alumina $(\mathrm{Al}-\mathrm{OH})$ faces (Hassan and Hameed 2011). The peak at $1635 \mathrm{~cm}^{-1}$ corresponded to $\mathrm{H}-\mathrm{O}-\mathrm{H}$ bending of interlayer water molecules. The relative reduction of the $1635 \mathrm{~cm}^{-1}$ peak in Fe-MC is due to loss of the loosely physisorbed water molecules by heating (Namduri and Nasrazadani 2008). This loss of hydroxyl groups may reduce the adsorption capacity of the clay for the target molecules. The band centered at $750 \mathrm{~cm}^{-1}$ corresponds to $\mathrm{Si}-\mathrm{O}-\mathrm{Al}$ vibrations (Hassan and Hameed 2011). The characteristic absorption bands of the $\mathrm{Fe}-\mathrm{O}$ bond in bulk magnetite $\left(\mathrm{Fe}_{3} \mathrm{O}_{4}\right.$ ) appear at $570 \mathrm{~cm}^{-1}$ and $375 \mathrm{~cm}^{-1}$ (Gonçalves et al. 2013), while maghemite $\left(\mathrm{Fe}_{2} \mathrm{O}_{3}\right)$ has several characteristic bands centered at $556 \mathrm{~cm}^{-1}, 638 \mathrm{~cm}^{-1}$ and $696 \mathrm{~cm}^{-1}$ (Konan et al. 2009). Therefore, the two bands located at $595 \mathrm{~cm}^{-1}$ and $684 \mathrm{~cm}^{-1}$ indicates the presence of maghemite $\left(\gamma-\mathrm{Fe}_{2} \mathrm{O}_{3}\right)$ phase. Furthermore, when $\mathrm{Fe}_{3} \mathrm{O}_{4}$ is heated at as low temperatures as $200-250{ }^{\circ} \mathrm{C}$ in an oxidizing atmosphere, as in the present work, $\left(\gamma-\mathrm{Fe}_{2} \mathrm{O}_{3}\right)$ is formed (Zhao et al. 2012).

\section{XRD analysis}

Figure 2 shows the XRD patterns of the raw clay and the Fe-MC. The dwarf diffraction peaks at $2 \theta=11.98^{\circ}, 20.70^{\circ}$, $21.30^{\circ}$, and $45.18^{\circ}$ correspond to kaolinite, while the sharp peaks at $2 \theta=26.48^{\circ}, 31.52^{\circ}$, and $42.28^{\circ}$ depict quartz as the other crystalline phase of the clay (Hassan and Hameed
2011). The diffractions at $2 \theta=30.08^{\circ}, 36.46^{\circ}$, and $42.3^{\circ}$ in $\mathrm{Fe}-\mathrm{MC}$ are characteristic of $\gamma-\mathrm{Fe}_{2} \mathrm{O}_{3}$ evidencing presence of iron in the impregnated clay and corroborates the findings from FTIR study. The slight noticeable decrease in the intensity of the quartz peak at $2 \theta=26.48^{\circ}$ in Fe-MC suggests subtle changes in crystallinity of quartz due to thermal treatment (Ercuta and Chirita 2013). Comparing the analogous peaks reveal increased disorder in Fe-MC than raw clay. The Fe-MC interlayer space was $7.28 \AA$ which is comparable to the dimensions of sulfonamides (Correa et al. 2006) making intercalation of the compounds possible.

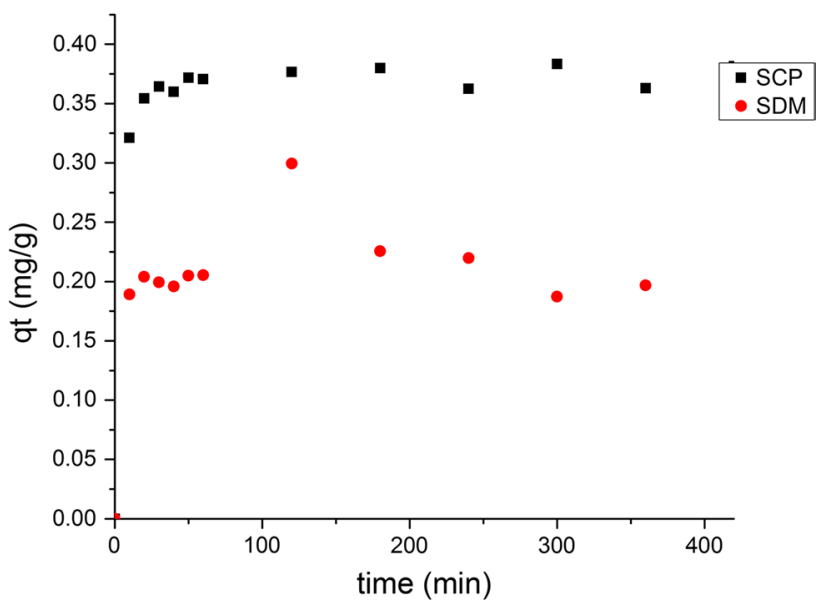

Fig. 3 Variation of adsorption capacity for SCP and SDM with time $\left(m=0.1 \mathrm{~g} / 50 \mathrm{~mL}, C_{i}=1 \mathrm{ppm}, \mathrm{pH}=6.4\right)$
Fig. 2 XRD diffractogram for the raw clay and $\mathrm{Fe}-\mathrm{MC}$

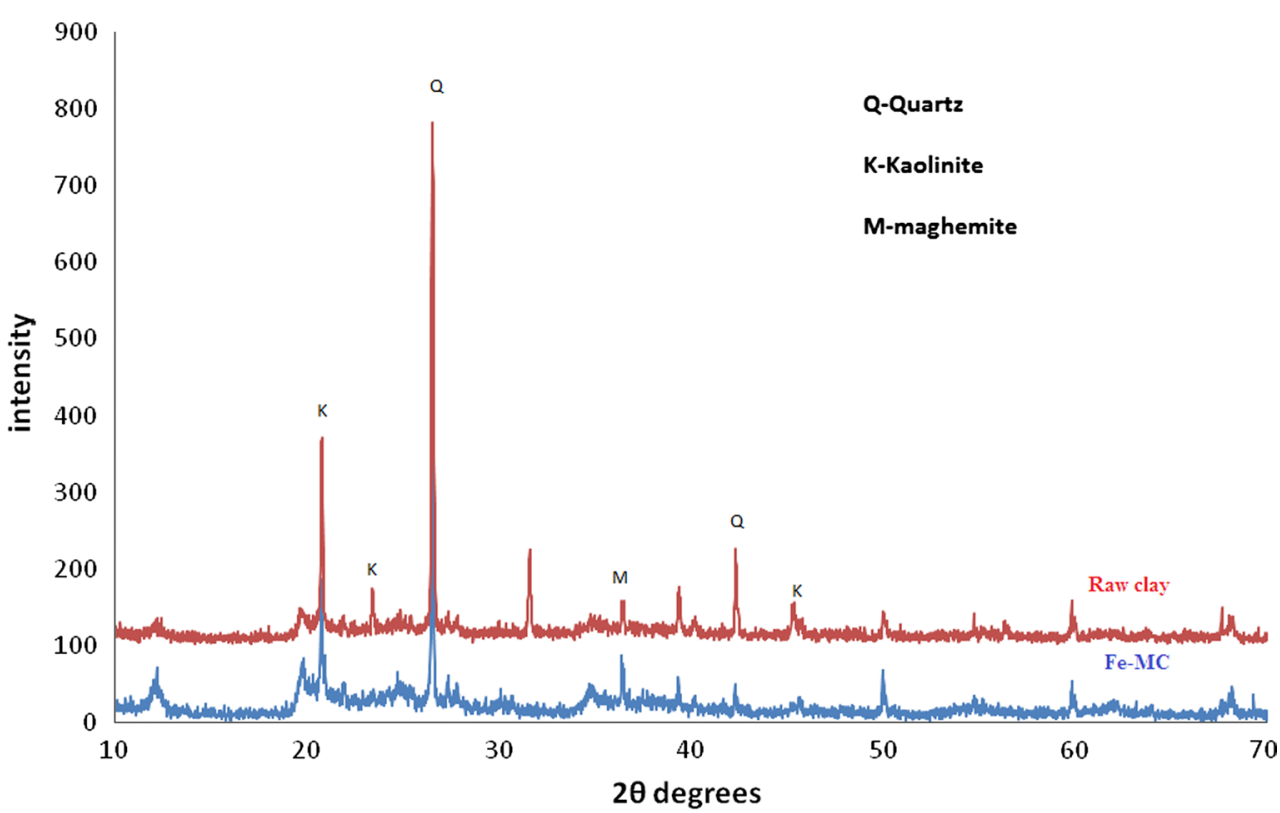




\section{Effect of contact time}

The variation of SCP and SDM retention by Fe-MC as a function of time indicated that the adsorption extent of the compounds increased rapidly to saturation within $120 \mathrm{~min}$ (Fig. 3) followed by a stagnated phase with no appreciable change, implying attainment of equilibrium conditions at this stage. The observed rapidity at the initial stages is due to a high solute concentration gradient and availability of completely bare active binding sites followed by the slow equilibrium phase attributed to saturation of the binding surfaces and repulsion between the adsorbed molecules and those in the bulk phase. Fe-MC exhibited higher removal efficiency for SCP (75\%) than SDM (45\%).

\section{Adsorption kinetics}

The adsorption dynamics were analyzed using linearized pseudo-first-order (Ho 2006) and pseudo-second-order kinetic models (Ho and McKay 1998). The conformity to the models was evaluated by the linear regression coefficient $\left(R^{2}\right)$ values and comparing the experimental equilibrium adsorption capacity $\left(q_{e \text {, exp }}\right)$ with the theoretical values $\left(q_{e, \text { cal }}\right)$ computed from the kinetic model.

Pseudo-first-order model: $\log \left(q_{e}-q_{t}\right)=\log q_{e}-\frac{k_{1} t}{2.303}$

Pseudo-second-order model: $\frac{t}{q_{t}}=\frac{1}{k_{2}\left(q_{e}\right)^{2}}+\frac{t}{q_{e}}$

where $t$ (mins) and $q_{t}\left(\mathrm{mg} \mathrm{g}^{-1}\right)$ are time and amount adsorbed at each time interval, respectively, while $q_{e}$

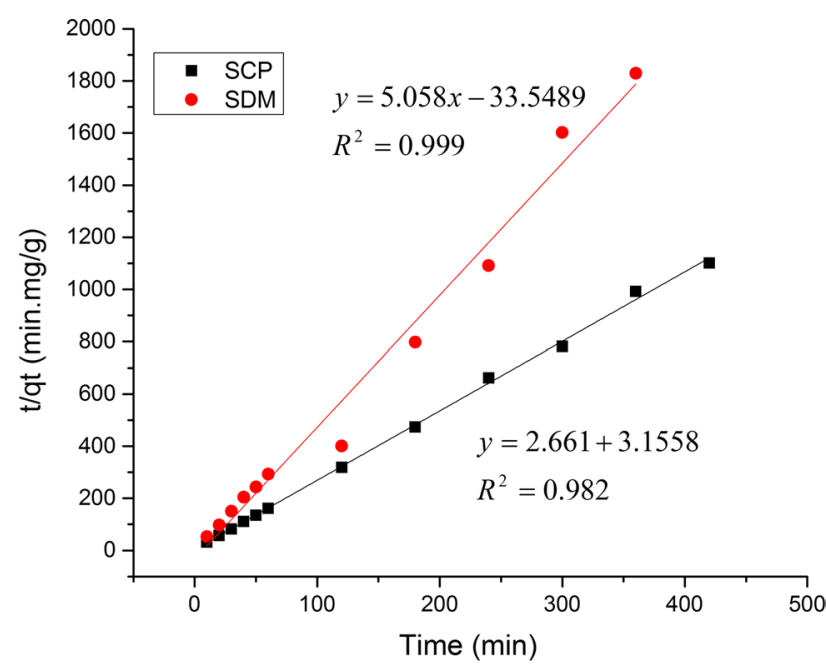

Fig. 4 Pseudo-second-order kinetic graph for adsorption of SCP and SDM onto Fe-MC $\left(m=0.1 \mathrm{~g} / 50 \mathrm{~mL}, C_{i}=1 \mathrm{ppm}, \mathrm{pH}=6.4\right)$
Table 3 Pseudo-second-order kinetic parameters for removal of SCP and SDM onto Fe-MC

\begin{tabular}{llllll}
\hline $\begin{array}{l}\text { Com- } \\
\text { pound }\end{array}$ & $\begin{array}{l}t_{1 / 2} \\
(\mathrm{mins})\end{array}$ & $\begin{array}{l}k_{2} \\
\left(\mathrm{~g} \mathrm{mg}^{-1} \mathrm{~min}^{-1}\right)\end{array}$ & $\begin{array}{l}q_{\mathrm{e}(\mathrm{cal})} \\
\left(\mathrm{mg} \mathrm{g}^{-1}\right)\end{array}$ & $\begin{array}{l}q_{\mathrm{e}(\mathrm{exp})} \\
\left(\mathrm{mg} \mathrm{g}^{-1}\right)\end{array}$ & $R^{2}$ \\
\hline $\mathrm{SCP}$ & 1.186 & 2.242 & 0.376 & 0.373 & 0.998 \\
$\mathrm{SDM}$ & 6.637 & 0.761 & 0.198 & 0.202 & 0.991 \\
\hline
\end{tabular}

$\left(\mathrm{mg} \mathrm{g}^{-1}\right)$ is the equilibrium adsorption capacity. $k_{1}$, and $k_{2}$ are rate constants.

The pseudo-first-order presented poor $R^{2}$ values, and the parameters are not herein presented. The mechanism of the adsorption does not follow pseudo-first-order kinetics which assumes one adsorbate molecule is attached to one binding site. The pseudo-second-order rate law described the adsorption systems under study with $R^{2}(>0.99)$ closest to unity (Fig. 4) corroborated with the close agreement between the calculated $\left(q_{\mathrm{cal}}\right)$ and experimental $\left(q_{\mathrm{exp}}\right)$ adsorption capacities (Table 3) with less than $2 \%$ deviation. The pseudosecond-order model assumes that one adsorbate molecule is sorbed onto two active sites of the clay. The adsorption half lives $\left(t_{1 / 2}\right)$ were computed from the pseudo-second-order regression plot using Eq. 5. The half-life values indicate SCP adsorption exhibited faster kinetics than SDM by five orders of magnitude.

$t_{1 / 2}=\frac{1}{k_{2} q_{e}}$

The kinetic data were also fitted to the intra-particle diffusion model (Weber and Morris 1963) to predict the ratecontrolling step. According to the model, if the plot of $q_{t}$

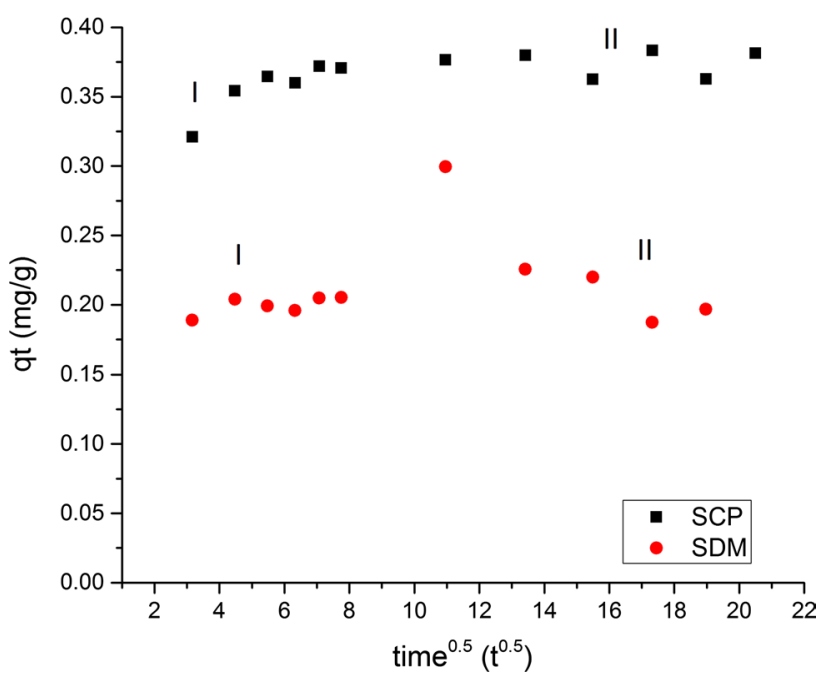

Fig. 5 Intra-particle diffusion graph for adsorption of SCP and SDM onto Fe-MC ( $m=0.1 \mathrm{~g} / 50 \mathrm{~mL}, C_{i}=1 \mathrm{ppm}, \mathrm{pH}=6.4$ ) 
versus $t^{0.5}$ is linear, then pore diffusion occurs, and if the plot passes through the origin, intra-particle diffusion is the only rate-controlling step.

Intra-particle model:

$q_{t}=k_{p} t^{0.5}+C$

where $q_{t}$ is the adsorption capacity of at a given time $t, k_{p}$ is the intra-particle rate constant in $\mathrm{mg} \mathrm{g}^{-1} \mathrm{~min}^{-1 / 2}$ while $C$ is a constant descriptive of the boundary layer thickness. Positive $C$ values depict boundary layer effects, while negative $C$ values denote no boundary layer effects on the adsorption rate (Elwakeel et al. 2014). As observed in Fig. 5, the plots were multi-linear (phases I and II) with nonzero intercepts implying the adsorption process occurred in phases and pore diffusion was not the sole operating rate-controlling step.

\section{Equilibrium adsorption}

\section{Effect of initial concentration}

The influence of initial SCP and SDM concentration on equilibrium adsorption capacity was evaluated and the results for each adsorbate are presented in Fig. 6. Equilibrium adsorption capacity for SCP increased from 0.18 to $0.37 \mathrm{mg} / \mathrm{g}$ $\mathrm{Fe}-\mathrm{MC}$ when the initial concentration was raised from 1 to $2 \mathrm{mg} / \mathrm{L}$. For similar initial concentrations, in case of SDM, adsorption capacities increase from 0.15 to $0.34 \mathrm{mg} / \mathrm{g}$. This fact depicts that mass gradient serves as the driving force for the adsorption process, and an increase in adsorbate molecules concentration in bulk solution at constant adsorbent dosage intensifies the mass transfer process. The increase in equilibrium adsorption capacity $\left(q_{e}\right)$ with increase in initial

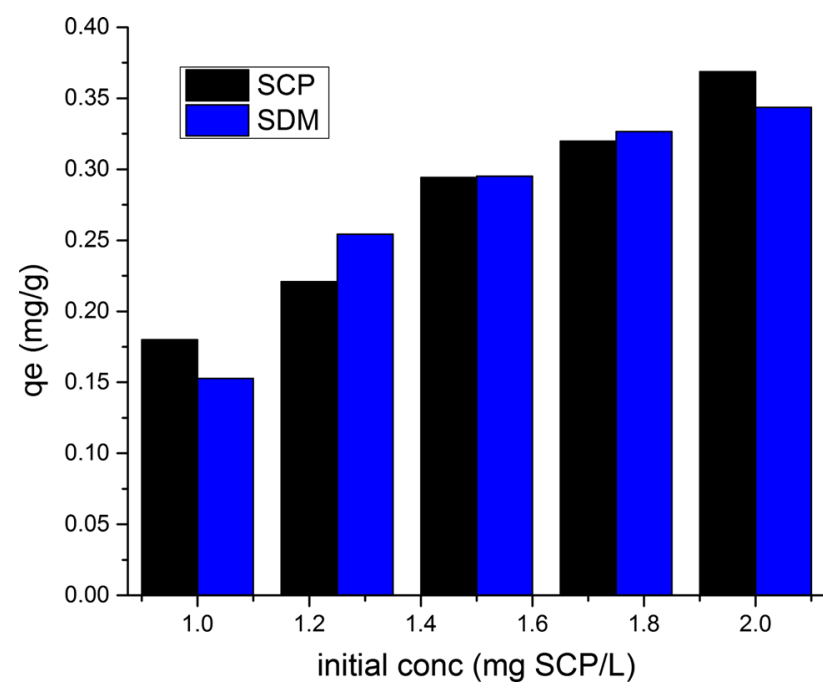

Fig. 6 Effect of initial concentration for adsorption of SCP and SDM onto Fe-MC $(m=0.1 \mathrm{~g} / 50 \mathrm{~mL}, \mathrm{pH}=6.4,303 \mathrm{~K})$

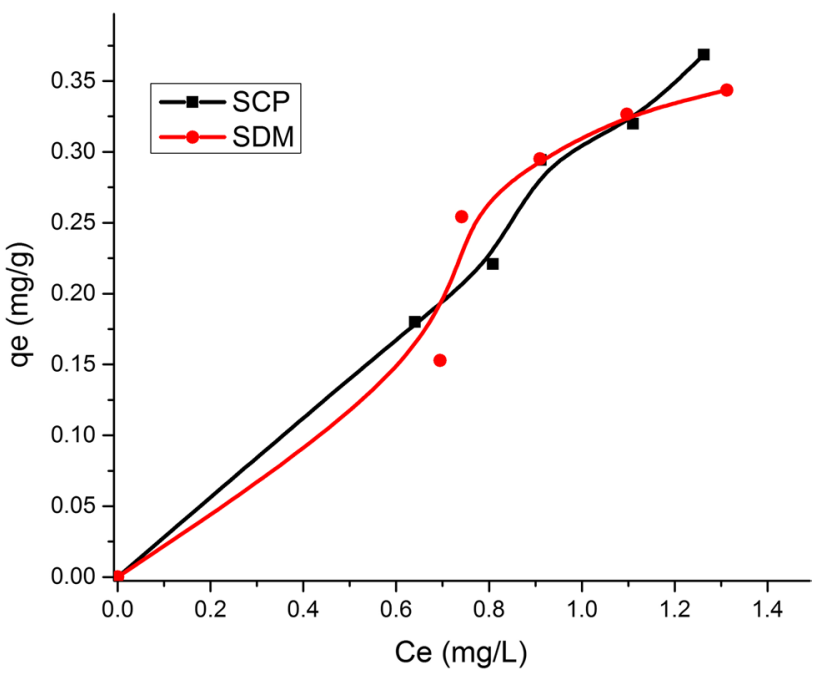

Fig. 7 Experimental adsorption isotherms SCP and SDM removal onto Fe-MC ( $\left.m=0.1 \mathrm{~g} / 50 \mathrm{~mL}, \mathrm{pH}=6.4,303 \mathrm{~K}, \mathrm{C}_{\mathrm{o}}=1-2 \mathrm{mg} / \mathrm{L}\right)$

adsorbate concentration indicates that $\mathrm{Fe}-\mathrm{MC}$ has a high adsorptive range for sulfonamides.

\section{Experimental adsorption isotherm}

Isothermal modeling is prerequisite for evaluating the distribution of the adsorbates between the aqueous and solid phases and the nature of the adsorbate-adsorbent interactions.

The experimental adsorption isotherms of SCP and SDM from the bulk solutions onto Fe-MC are presented in Fig. 7.

The nature of specific adsorption mechanisms was diagnosed from the shape of the experimental isotherms. Giles et al. (1974) classified isotherms for adsorption of organic solutes into four main groups: $\mathrm{L}, \mathrm{S}, \mathrm{H}$, and $\mathrm{C}$ and thereafter into subgroups. Following the aforementioned classification, the isotherms of SCP and SDM displayed an S-type curve structure. The $\mathrm{S}$-shaped adsorption isotherms denote vertical orientation of the adsorbed molecules at the adsorbent surface and presence of strong competition between the adsorbing compounds and the solvent molecules for the binding sites. The curves can be seen to rise steadily with no clear plateau implying that the orientation of the adsorbed molecules presents new surfaces with high attraction for more solutes. It is a testament for side-by-side association of adsorbed molecules or the so-called cooperative adsorption.

\section{Fitting Langmuir isotherm}

The sorption data were analyzed according to the linear form of the Langmuir isotherm (Table 4) and the isotherm constants; $K_{L}$ the Langmuir equilibrium constant $\left(\mathrm{L} \mathrm{mg}^{-1}\right)$ related to the free energy of adsorption, $Q_{o}$ the maximum 
adsorption capacity $\left(\mathrm{mg} \mathrm{g}^{-1}\right)$, and the coefficients of determination, $R^{2}$ are presented in Table 5. Based on $\mathrm{R}^{2}$ values, the Langmuir model seemed to be best fitting for SCP adsorption. However, despite the higher $R^{2}$ values for SCP adsorption onto Fe-MC over SDM, the negative Langmuir isotherm constants $\left(Q_{o}\right.$ and $K_{L}$ ) values for both compounds bore no physical meaning and are unacceptable. This depicts that the underlying assumptions of Langmuir modelization are incapable to satisfactorily explain the adsorption of SDM and SCP onto Fe-MC and would yield dimensionless separation constant $\left(R_{L}\right)$ value greater than 1 (Shikuku et al. 2015). This may suggest a change in adsorption mechanism compared to adsorption of SCP and SDM onto untreated kaolinite clay under similar conditions which conformed to linearized Langmuir equation as reported in our previous work (Shikuku et al. 2017). Alternatively, this observation may also be attributed to the inherent error structures associated with transformation of nonlinear functions to linear models (Nagy et al. 2017). Linearization process can violate the theories underneath the model and the estimated parameters may not necessarily represent the same values for the original nonlinear equation. To overcome this problem, the SCP and SDM equilibrium adsorption data were fitted to the original nonlinear Langmuir equation (Table 6) to ascertain that the adsorption mechanisms are not governed by postulates of the Langmuir model as implied by the linear regression analysis.

\section{Fitting Freundlich isotherm}

For the Freundlich model (Table 4), $K_{f}$ and $n$ are Freundlich constants depictive of the relative adsorption capacity and adsorption favorability or surface heterogeneity of the adsorbent, respectively. According to Treybal (1981), the values of $n$ in the range 2-10 represent good, 1-2 moderately difficult, and less than 1 a poor adsorptive property. The linear form and calculated constants of Freundlich model are presented in Table 5. Accordingly, the magnitudes of $n$, tending to unity, indicate moderately difficult adsorptive process. Nevertheless, from the $\mathrm{R}^{2}$ values, linear Freundlich model better fitted the adsorption of SCP and SDM over Fe-MC compared to linear Langmuir equation. Furthermore, the $1 / n$ values above unity suggest cooperative adsorption involving multiple mechanisms as alluded to by the S-type isotherm pattern (Saleh 2015).

\section{Fitting Temkin isotherm}

For the Temkin isotherm equation (Table 4), $T$ is temperature $(\mathrm{K}), R$ is the universal gas constant $(8.314 \mathrm{~J} / \mathrm{mol} . \mathrm{K}), A_{T}$ is the equilibrium binding constant $(\mathrm{L} / \mathrm{mg}), b_{T}$ represents the variation in adsorption energy $(\mathrm{kJ} / \mathrm{mol})$, and $B_{T}$ is Temkin constant associated with the parameter $b_{T}$ by the relation:

$b_{T}=\frac{R T}{B}$
Table 4 Linearized isotherm equations and parameters

\begin{tabular}{lllll}
\hline Isotherm Model & Nonlinear form & Linear form & Parameters & Reference \\
\hline Langmuir & $q_{e}=Q_{o} \frac{K_{L} C_{e}}{1+K_{L} C_{e}}$ & $\frac{1}{q_{e}}=\frac{1}{Q_{o}}+\frac{1}{Q_{o} K_{L} C_{e}}$ & $\begin{array}{l}Q_{o}(\mathrm{mg} / \mathrm{g}), \\
K_{L}(\mathrm{~L} / \mathrm{g})\end{array}$ & Langmuir (1916) \\
Freudlich & $q_{e}=K_{f} C_{e} / n$ & $\log q_{e}=\log K_{f}+\frac{1}{n} \log C_{e}$ & $K_{f}, \mathrm{n}$ & $\begin{array}{c}\text { Freundlich } \\
(1906)\end{array}$ \\
Temkin & $q_{e}=B \ln A_{T} . C_{e}$ & $q_{e}=B \ln A_{T}+B \ln C_{e}$ & $A_{T}, \mathrm{~B}$ & Temkin (1941) \\
\hline
\end{tabular}

Table 5 Calculated adsorption isotherm values using linear regression analysis

\begin{tabular}{|c|c|c|c|c|c|c|c|c|c|}
\hline & \multicolumn{3}{|c|}{ Langmuir coefficients } & \multicolumn{3}{|c|}{ Freundlich coefficients } & \multicolumn{3}{|c|}{ Temkin coefficients } \\
\hline & $Q_{0} \mathrm{mg} / \mathrm{g}$ & $K_{L} \mathrm{~L} / \mathrm{mg}$ & $R^{2}$ & $n$ & $K_{f} \mathrm{~L} / \mathrm{mg}$ & $R^{2}$ & $b_{T} \mathrm{~kJ} / \mathrm{mol}$ & $A_{T} \mathrm{~L} / \mathrm{mg}$ & $R^{2}$ \\
\hline SCP & -2.915 & $-9.110 \times 10^{2}$ & 0.961 & 0.939 & 0.293 & 0.955 & 9.029 & 2.290 & 0.960 \\
\hline SDM & -1.264 & -0.185 & 0.669 & 0.970 & 0.286 & 0.703 & 9.914 & 3.182 & 0.794 \\
\hline
\end{tabular}

Table 6 Calculated adsorption isotherm values using nonlinear regression analysis

\begin{tabular}{|c|c|c|c|c|c|c|c|c|c|}
\hline & \multicolumn{3}{|c|}{ Langmuir coefficients } & \multicolumn{3}{|c|}{ Freundlich coefficients } & \multicolumn{3}{|c|}{ Temkin coefficients } \\
\hline & $Q_{0} \mathrm{mg} / \mathrm{g}$ & $K_{L} \mathrm{~L} / \mathrm{mg}$ & $\mathrm{R}^{2}$ & $n$ & $K_{f} \mathrm{~L} / \mathrm{mg}$ & $R^{2}$ & $b_{T} \mathrm{~kJ} / \mathrm{mol}$ & $A_{T} \mathrm{~L} / \mathrm{mg}$ & $R^{2}$ \\
\hline SCP & 4.561 & 0.069 & 0.997 & 0.977 & 0.293 & 0.953 & 9.029 & 2.924 & 0.998 \\
\hline SDM & 1.789 & 0.193 & 0.756 & 1.162 & 0.289 & 0.748 & 9.878 & 3.175 & 0.794 \\
\hline
\end{tabular}


Temkin model postulates that the heat of adsorption of all the adsorbates in layer decreases linearly with coverage due to adsorbent-adsorbate interactions (ShahmohammadiKalalagh et al. 2011). The calculated parameters for the linear form of Temkin model are shown in Table 5. The Temkin constant, $b_{T}$, linked to the heat of adsorption for the two compounds were $9.029 \mathrm{~kJ} / \mathrm{mol}$ and $9.917 \mathrm{~kJ} / \mathrm{mol}$ for SCP and SDM, respectively. The typical bonding energy for a physisorption mechanism is reported to fall in the range $8-16 \mathrm{~kJ} /$ mol (Shahmohammadi-Kalalagh et al. 2011). The values in the present work imply a physisorption controlled mechanism characterized by relatively weak adsorbent-adsorbate interactions. Therefore, from the linear regression analysis, the best fitting isotherms were in the order Temkin followed by Freundlich then Langmuir model.

\section{Nonlinear analysis}

Nonlinear regression of equilibrium sorption data for each isotherm was performed by minimizing the regression sum of squares (RSS) error function using the solver add-in with excel's spreadsheet, Excel (Microsoft), and the calculated constants and the coefficients of determination are presented in Table 6. The RSS error function was obtained as the sum of the squares of the differences between the experimental data and data values predicted by the models. Mathematically, this is represented as:

$\operatorname{RSS}=\sum_{1}^{N}\left(q_{e, \text { experimental }}-q_{e, \text { predicted }}\right)^{2}$

where $N$ is the number of data points. In the nonlinear analysis, there was significant variation in the Langmuir constants and $R^{2}$ values. From the $R^{2}$ values, the adsorption of SCP was describable by the Langmuir model. Unlike in linear regression, all the constants were positive. The Langmuir monolayer maximum adsorption capacities were 4.561 and $1.789 \mathrm{mg} / \mathrm{g}$ for SCP and SDM, respectively. It is evident therefore that linearization contributed in the violation of the theoretical basis of the model. The results demonstrate that while linear regression is widely used to determine isotherm models of best fit; nonlinear regression is a better analytical method to avoid errors in estimation of isotherm parameters and prediction of best fit models. There was no significant variation in the constants and $R^{2}$ values for the nonlinear

Table 7 Single and binary adsorption of SCP and SDM onto Fe-MC

\begin{tabular}{lll}
\hline Adsorption capacity $(\mathrm{mg} / \mathrm{g})$ & SCP & SDM \\
\hline Single component $\left(q_{s, i}\right)$ & 0.362 & 0.203 \\
Binary component $\left(q_{b, i}\right)$ & 0.226 & 0.209 \\
\hline
\end{tabular}

Freundlich and Temkin isotherms relative to linear analysis. Based on $R^{2}$ values, the best fitting models were in the order Temkin $>$ Langmuir $>$ Freundlich.

\section{Binary component competitive adsorption}

The equilibrium experimental data for the simultaneous adsorption of SCP onto Fe-MC in the presence of an equal concentration of SDM $\left(1 \mathrm{mg} \mathrm{L}{ }^{-1}\right)$ is shown in Table 7.

The effect of the simultaneous presence of the two compounds, on the bi-component extraction efficiency of Fe-MC was evaluated by computing the ratio of the equilibrium adsorption capacity $\left(R_{q}\right)$, defined as (Istratie et al. 2016):

$R_{q, i}=\frac{q_{b, i}}{q_{s, i}}$

where $q_{b, i}$ and $q_{s, i}$ are the equilibrium adsorption capacity $\left(q_{e}\right)$ of compound $i$ in the binary solution and in the singlecomponent solution, respectively, under similar experimental conditions. According to Istratie et al. (2016); when $R_{q, i}>1$, the presence of another adsorbate in a bi-component system enhances the adsorption of pollutant $i$ (i.e., synergistic adsorption), if $R_{q, i}=1$, there is no effect of the presence of the other adsorbate in the binary system on the adsorption of pollutant $i$ and if $R_{q, i}<1$, the retention of pollutant $i$ is reduced by the presence of the other pollutant (i.e., antagonistic adsorption).

The adsorption of SCP was significantly reduced by the presence of SDM in the bi-component system. The equilibrium adsorption capacity of SCP decreased from $0.362 \mathrm{mg} / \mathrm{g}$ in the single-component solution to $0.226 \mathrm{mg} / \mathrm{g}$ in the binary solution (Fig. 6). The value $R_{q, \mathrm{SCP}}=0.625$ is much less than 1 confirming antagonistic adsorption of SCP in the presence of SDM.

By contrast, SDM adsorption was practically unaffected by the presence of SCP in the binary system. The equilibrium adsorption capacity of SDM was $0.203 \mathrm{mg} / \mathrm{g}$ in single-component solution and $0.2096 \mathrm{mg} / \mathrm{g}$ in binary solution, resulting to the value $R_{q, \mathrm{SDM}}=1.032$, almost equivalent to 1 . There was observed a decrease in SCP uptake in the presence of SDM $\left(R_{q, \mathrm{SCP}}=0.625\right)$ while SDM adsorption was kept variably constant $\left(R_{q, \mathrm{SDM}}=1.032\right)$ implying much stronger interactions between SDM and the Fe-MC binding sites than those involved in SCP adsorption. The results also indicate that SCP and SDM do not share some binding sites hence exhibit different adsorption mechanisms. Noteworthy, the antagonistic phenomenon observed is opposite to that reported for the raw clay under similar conditions (Shikuku et al. 2017). This suggests the introduction of iron produces surfaces with higher affinity for SDM relative to the untreated clay. 
Table 8 Thermodynamic parameters for SCP and SDM adsorption onto $\mathrm{Fe}-\mathrm{RC}$

\begin{tabular}{llllllll}
\hline Compound & Temp (K) & $\begin{array}{l}\text { Adsorption } \\
\text { capacity } \\
(\mathrm{mg} / \mathrm{g})\end{array}$ & $\Delta \mathrm{G}(\mathrm{kJ} / \mathrm{mol})$ & $\Delta \mathrm{H}(\mathrm{kJ} / \mathrm{mol})$ & $\Delta \mathrm{S}(\mathrm{J} / \mathrm{mol})$ & $\mathrm{E}_{\mathrm{a}}(\mathrm{kJ} / \mathrm{mol})$ & $\mathrm{S}^{\mathrm{a}}$ \\
\hline $\mathrm{SCP}$ & 303 & 0.465 & -15.302 & & & & \\
& 313 & 0.444 & -15.586 & -7.562 & 25.570 & 4.219 & 0.0873 \\
& 323 & 0.419 & -15.812 & & & & \\
$\mathrm{SDM}$ & 303 & 0.362 & -14.230 & & & & \\
& 313 & 0.343 & -14.487 & -7.594 & 29.930 & 5.004 & 0.0498 \\
& 323 & 0.320 & -14.667 & & & & \\
\hline
\end{tabular}

${ }^{\text {a }}$ Distinguish between entropy ( $\mathrm{S}$ ) and the sticking probability also denoted by $\mathrm{S}$

\section{Adsorption thermodynamics}

Generally, temperature changes have two diverse effects on an adsorption process: Under pre-equilibrium conditions, it alters the rate of adsorption, while after the equilibrium is attained, temperature changes alter the position of adsorption equilibrium of the adsorbent for a given adsorbate.

When the temperature was raised from 303 to $323 \mathrm{~K}$, the amount of SCP and SDM adsorbed after equilibrium decreased (Table 8) consistent with an exothermic adsorption process. The decrease is attributed to the shifting of the equilibrium toward desorption with rise in temperature with concomitant weakening of the adsorbate-adsorbent interactions. The observed decrease can also be attributed to increased molecular mobility hence declension in the chemical affinity of the adsorbates for the Fe-MC surface and accordingly the molecules escape from the Fe-MC surface into the liquid phase.

The thermodynamic parameters, namely change in free energy $(\Delta \mathrm{G})$, enthalpy $(\boldsymbol{\Delta H})$, and entropy $(\boldsymbol{\Delta S})$ (Table 8$)$, which indicate the practical feasibility of the process, postadsorption structural changes of the adsorbent and the adsorption mechanism, were derived from the van't Hoff equation:

$\ln K_{c}=\frac{-\Delta H}{R T}+\frac{S}{R}$

$K_{d}=\frac{q_{e}}{C_{e}}$

$\Delta G=-R T \ln K_{c}$

where $K_{d}$ is the distribution coefficient, $T$ is the temperature (in Kelvin) and $R$ is the universal gas constant $(8.314 \mathrm{~J} /$ $\mathrm{mol} \mathrm{K}$ ), and $K_{c}$ is the equilibrium constant (dimensionless). The linear regression for van't Hoff equation afforded high coefficients of determination, and the plots are displayed in Fig. 8.

The negative values of enthalpy change $(\Delta \mathrm{H})$ verified the exothermic nature of the adsorption processes and are

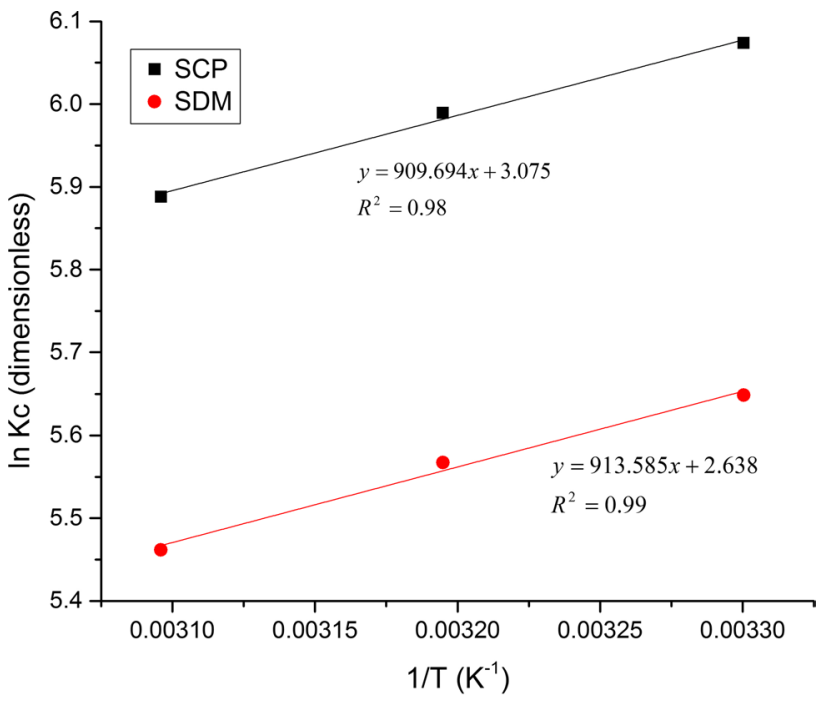

Fig. 8 van't Hoff plots for adsorption of SCP and SDM onto Fe-MC $(m=0.1 \mathrm{~g} / 50 \mathrm{~mL}, \mathrm{pH}=6.4)$

unfavored by rise in temperature. In the literature, magnitudes of $\Delta \mathrm{H}$ below $40 \mathrm{kJmol}^{-1}$ are reported to depict physisorption mechanisms (Atkin 1990). The calculated $\Delta H$ values in the present work (Table 5) testify that physisorption is the adsorption mechanism of SCP and SDM onto Fe-MC. Generally, $\Delta \mathrm{G}$ values for physisorption range between 0 and $20 \mathrm{~kJ} \mathrm{~mol}^{-1}$, while chemisorptions are between 80 and $400 \mathrm{~kJ} \mathrm{~mol}^{-1}$ (Atkin 1990). Gibbs free energy change $(\Delta G)$ is an important criterion of spontaneity. Thus, the magnitude of the negative $\Delta \mathrm{G}$ values indicated that the adsorption of both compounds onto $\mathrm{Fe}-\mathrm{MC}$ is a thermodynamically spontaneous and physically controlled process, under the experimental conditions. Furthermore, the $\Delta \mathrm{G}$ values increased with rising temperature, reaffirming the exothermic nature of the reactions exceeded the effect of increasing the molecules' diffusion rate. The positive values of entropy change $(\Delta S)$ correspond to decrease in molecular orderliness at the solid/liquid interface of the adsorption process and increase in degree of freedom of the adsorbed molecules. The negative $\Delta \mathrm{G}$ values associated with an exothermic process with positive $\Delta S$ values imply that the adsorption process is enthalpy-driven. 


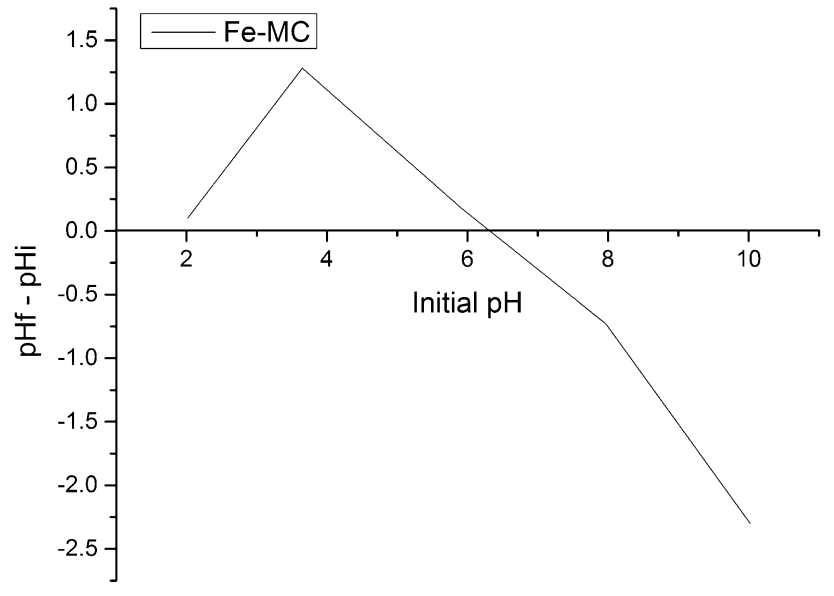

Fig. 9 Point of zero charge $\left(\mathrm{pH}_{\mathrm{pzc}}\right)$ of Fe-MC

To further ascertain that physisorption is the predominant adsorption mechanism, the adsorption activation energy $\left(\mathrm{E}_{\mathrm{a}}\right)$ and sticking probability $\left(\mathrm{S}^{*}\right)$ were computed from experimental data using modified Arrhenius-type equation related to surface coverage $(\theta)$ by Mahmoud et al. (2016):

$S^{*}=(1-\theta) e^{-E_{a} / R T}$

The $S^{*}$ is dependent on the adsorbate-adsorbent system under study, its value lies in the range $0<S^{*}<1$ and is a function of temperature of the system. The value of $\theta$ was calculated from the following relation:

$\theta=\left[1-\frac{C_{e}}{C_{0}}\right]$

The magnitude of activation energy gives further insight on whether the adsorption involves a physical or chemical process. Generally, physisorption processes have energies in the range of $5-40 \mathrm{~kJ} / \mathrm{mol}$, while higher activation energies (40-800 $\mathrm{kJ} \mathrm{mol}^{-1}$ ) point to a chemisorption mechanism [34]. The $\mathrm{E}_{\mathrm{a}}$ values for the adsorption of SCP and SDM onto the treated clay were in the range $4-5 \mathrm{~kJ} \mathrm{~mol}^{-1}$, strengthening the aforementioned hypothesis of physisorption being the adsorption mechanism. These values also indicate the existence of a low potential energy barrier.

\section{Adsorption mechanism}

In order to understand the adsorption mechanisms and the adsorbates-adsorbent interactions, the surface charge, functional groups present and composition of the adsorbent relative to the physicochemical properties of SCP and SDM were analyzed. Several possible adsorption mechanisms reported for sulfonamides were considered, namely: (1) hydrophobic partitioning; (2) electrostatic attraction; (3) cation bridging (4) hydrogen bonding; and (4) negative charge-assisted H-bond [(-) CAHB] (Teixidó et al. 2011). The higher removal efficiency for SCP $\left(\log \mathrm{K}_{\mathrm{ow}} 0.31\right)$ than SDM $\left(\log \mathrm{K}_{\mathrm{ow}} 1.17\right)$ depicted that other mechanisms besides hydrophobic interaction were involved in adsorption process. Furthermore, changes from neutral to anionic form increase the hydrophilicity of the sulfonamides and thus hydrophobic interactions become significantly lessened (Teixidó et al. 2011). Electrostatic interactions are known to influence sorption of ionic compounds. In the present study, SCP and SDM molecules $\left(\mathrm{pK}_{\mathrm{a}}=5.7\right)$ were mostly anionic under the circumneutral experimental conditions ( $\mathrm{pH}$ of 6.4). The $\mathrm{pH}$ of point of zero charge $\left(\mathrm{pH}_{\mathrm{pzc}}\right)$ of Fe-MC, which is an index of the clay mineral layer (surface) charge as a function of $\mathrm{pH}$, was about 6.2 (Fig. 9), and therefore the net surface charge of the adsorbent was negative at $\mathrm{pH}>6.2$. This implies that the adsorption of SCP and SDM onto Fe-MC could not be explained in terms coulombic attractions.

From XRD analysis, Fe-MC contained several metal oxide species. These multivalent cations may promote adsorption of the negatively charged species $\left(\mathrm{SCP}^{-}\right.$and $\mathrm{SDM}^{-}$) by surface bridging with these anions. Therefore, the adsorption of SCP and SDM may be partly attributed to cation bridging interactions. Furthermore, the similarity in the $\mathrm{pK}_{\mathrm{a}}$ values (5.7) and the $\mathrm{pH}_{\mathrm{pzc}}$ (6.2) makes it conceivable that strong (-) CAHB forms between the anionic SCP/SDM species and the Fe-MC surface hydroxyl groups. This would involve proton exchange with water molecules as shown in Eq. 14 releasing $-\mathrm{OH}$ into the solution. The $-\mathrm{OH}$ would then be neutralized by deprotonation of the Fe-MC surface hydroxyl groups by formation of negative charge-assisted H-bond [(-) CAHB] (Eq. 15) as schematically presented in Fig. 10.

Sulfonamide $-\mathrm{N}^{-}+\mathrm{H}_{2} \rightarrow \mathrm{O}$ Sulfonamide $-\mathrm{NH}+\mathrm{OH}^{-}$

$$
\begin{aligned}
& \text { Sulfonamide }-\mathrm{NH}+\mathrm{HO} \mathrm{Fe}-\mathrm{MC} \\
& \quad \rightarrow \text { Sulfonamide }-\mathrm{N}^{-} \mathrm{H}^{+} \mathrm{O}-\mathrm{Fe}-\mathrm{MC}+\mathrm{H}^{+}
\end{aligned}
$$

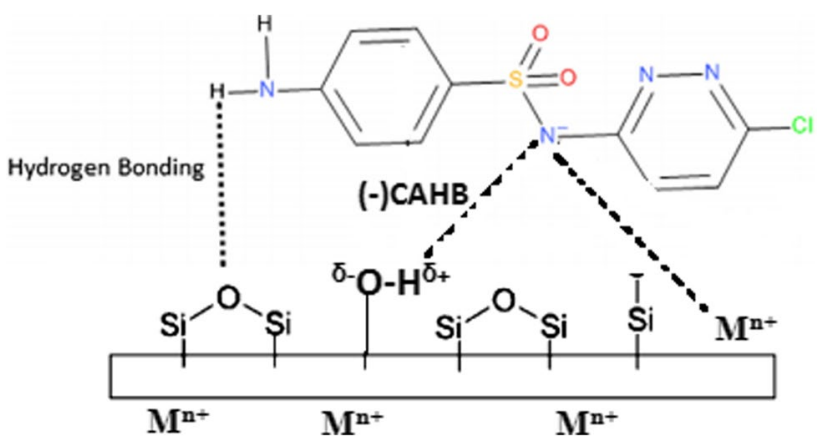

Fig. 10 Possible adsorption mechanism of SCP on Fe-MC 


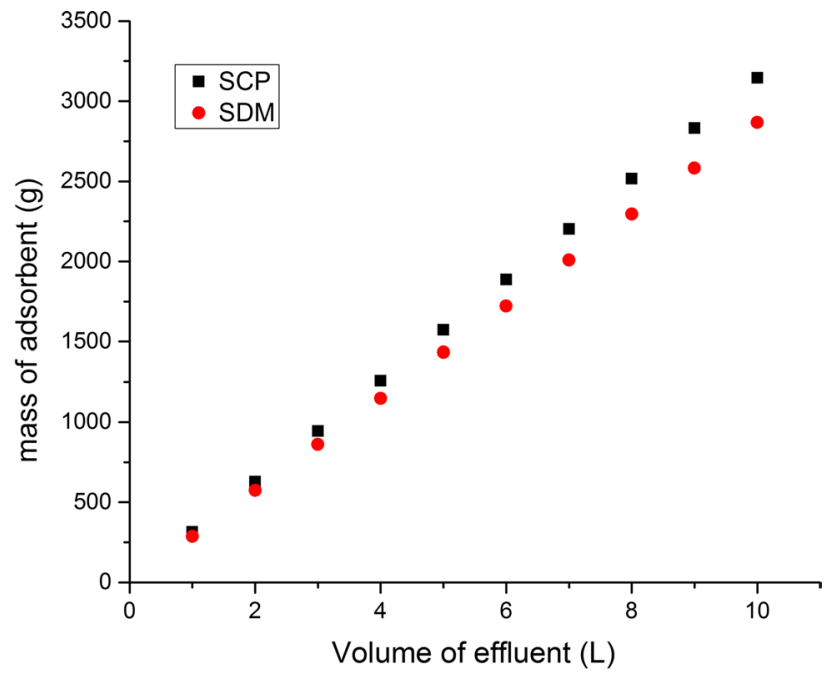

Fig. 11 Variation of the theoretical mass of Fe-MC with volume required for SCP and SDM effluents to be treated for 99\% removal efficiency with initial concentration of $0.2 \mathrm{mg} \mathrm{L}^{-1}$ at $303 \mathrm{~K}$

Similar affinity between molecules with comparable $\mathrm{pK}_{\mathrm{a}}$ to surface hydroxyl groups have been reported for sorption of sulfamethoxazole (SMX) and sulfamethazine (SMZ) on biochars (Huang et al. 2015; Lian et al. 2014). Iron leaching into the solution from the adsorbent matrix was monitored using AAS and was below the instrumental LOQ $(0.01 \mathrm{mg}$ $\left.\mathrm{L}^{-1}\right)$.

\section{Batch reactor design}

Adsorption isotherms are useful tools for prediction the design of batch adsorption systems. In this case, the purpose of the prototype is to estimate the mass of adsorbent, $m(\mathrm{~g})$, required to remove SCP and SDM from solution of volume $V(\mathrm{~L})$, at near real environmental initial concentration of $C_{o}$ to relatively permissible levels of concentration $C_{e}\left(\mathrm{mg} \mathrm{L}^{-1}\right)$.

Based on the Langmuir isotherm model, the mass of Fe-MC, $m(\mathrm{~g})$, required for realizing specified percentage removal efficiency $(R)$ from aqueous solution of volume $V$ (L) for a known initial concentration of SCP or SDM $C_{o}(\mathrm{mg}$ $\mathrm{L}^{-1}$ ), except for $100 \%$ removal efficiency was calculated by the relation (Shikuku et al. 2017):

$m=\frac{V R C_{o}\left(1+K_{L}\left(C_{o}(1-R / 100)\right)\right)}{100 Q_{o} K_{L}\left(C_{o}(1-R / 100)\right)}$

The mass of Fe-MC required to achieve 99\% removal of $0.2 \mathrm{mg} \mathrm{L}^{-1} \mathrm{SCP}$ and SDM from solutions of varied volumes $(1-10 \mathrm{~L})$ at $303 \mathrm{~K}$, in a single solute batch reactor system is presented in Fig. 11. The mass of adsorbent needed increases with increase in solution volume.

\section{Conclusion}

In this work, naturally occurring kaolinite clay was chemically treated with iron by co-precipitation and the product (Fe-MC) applied for sulfonamide sequestration from synthetic wastewater. Fe-MC showed relatively higher adsorption capacity for SCP than SDM. Nonlinear Temkin and Langmuir isotherm models suitably described the equilibrium sorption data. The results show that linearization of adsorption isotherms induces inherent errors that can significantly affect estimation of the isotherm parameters. Adsorption kinetics followed pseudo-second-order kinetics while thermodynamics investigation revealed the adsorption process to be spontaneous and exothermic. The magnitude of $E_{a}$ value for adsorption of both sulfonamides indicated that the adsorption mechanism was physical in nature. Hydrogen bonding, Cation bridging and negative charge-assisted $\mathrm{H}$-bonding $[(-) \mathrm{CAHB}]$ are determined as the possible mechanisms of adsorption of SCP and SDM onto Fe-MC.

Acknowledgements The authors acknowledge www.exceed-swind on.org for the student exchange fellowship awarded to the first author and the collaboration between the institutions involved and the National Research Fund (Kenya) for providing funding to facilitate the work.

Open Access This article is distributed under the terms of the Creative Commons Attribution 4.0 International License (http://creativeco mmons.org/licenses/by/4.0/), which permits unrestricted use, distribution, and reproduction in any medium, provided you give appropriate credit to the original author(s) and the source, provide a link to the Creative Commons license, and indicate if changes were made.

\section{References}

Atkin PW (1990) Physical chemistry, 4th edn. Oxford University Press, London

Baran W, Adamek E, Justyna Z, Andrzej S (2011) Effects of the presence of sulfonamides in the environment and their influence on human health. J Hazard Mater 1-15(30):196

Białk-bielińska A, Stolte S, Arning J, Uebers U, Böschen A, Stepnowski P, Matzke M (2011) Ecotoxicity evaluation of selected sulfonamides. Chemosphere 85:928-933

Boruah PK, Borah DJ, Handique J, Sharma P, Sengupta P, Das MR (2015) Facile synthesis and characterization of $\mathrm{Fe}_{3} \mathrm{O}_{4}$ nanopowder and $\mathrm{Fe}_{3} \mathrm{O}_{4} /$ reduced graphene oxide nanocomposite for methyl blue adsorption: a comparative study. J Environ Chem Eng 3:1974-1985

Correa JR, Canetti D, Castillo R, Llópiz JC, Dufour J (2006) Influence of the precipitation $\mathrm{pH}$ of magnetite in the oxidation process to maghemite. Mater Res Bull 41:703-713

Elwakeel KZ, Atia AA, Guibal E (2014) Fast, Removal of uranium from aqueous solutions using tetraethylenepentamine modified magnetic chitosan resin. Bioresour Technol 160:107-114 
Ercuta A, Chirita M (2013) Highly crystalline porous magnetite and vacancy-ordered maghemite microcrystals of rhombohedral habit. J Cryst Growth 380:182-186

Freundlich HMF (1906) U“ ber die adsorption in lo"sungen. Z Phys Chem 57:385-470

Giles CH, D'Silva AP, Easton IA (1974) A general treatment and classification of the solute adsorption isotherm. I Theor J Colloid Interface Sci 47:766

Gonçalves M, Guerreiro MC, Oliveira LC, Soares C (2013) A friendly environmental material: iron oxide dispersed over activated carbon from coffee husk for organic pollutants removal. J Environ Manag 127:206-211

Hassan H, Hameed BH (2011) Fe-clay as effective heterogeneous fenton catalyst for the decolorization of reactive blue 4. Chem Eng J 171:912-918

Ho YS (2006) Review of second-order models for adsorption systems. J Hazard Mater 136:681-689

Ho YS, McKay G (1998) Sorption of dye from aqueous solution by peat. Chem Eng J 70:115-124

Hosseinzadeh H, Mohammadi S (2015) Quince seed mucilage magnetic nanocomposites as novel bioadsorbents for efficient removal of cationic dyes from aqueous solutions. Carbohydr Polym 134:213-221

Huang X, Yi F, Cui Hu, Xiaoyu X, Daliang Y, Xiaoming Z (2015) Mechanistic QSAR models for interpreting degradation rates of sulfonamides in UV-photocatalysis systems. Chemosphere 138:183-189

Istratie R, Marcela S, Cornelia P, Cosmin L (2016) Single and simultaneous adsorption of methyl orange and phenol onto magnetic iron oxide/carbon nanocomposites. J Chem, Arab. https://doi. org/10.1016/j.arabjc.2015.12.012

Kimosop SJ, Getenga ZM, Orata F, Okello VA, Cheruiyot JK (2016) Residue levels and discharge loads of antibiotics in wastewater treatment plants (WWTPs), hospital lagoons, and rivers within Lake Victoria Basin, Kenya. Environ Monit Assess 188:532. https ://doi.org/10.1007/s10661-016-5534-6

Kolpin DW, Furlong ET, Meyer MT, Thurman EM, Zaugg SD, Barber LB, Buxton HT (2002) Pharmaceuticals, hormones, and other organic wastewater contaminants in U.S. streams, 1999-2000: a national reconnaissance. Environ Sci Technol 36:1202-1211

Konan KL, Peyratout C, Smith A, Bonnet JP, Rossignol S, Oyetola S (2009) Comparison of surface properties between kaolin and metakaolin in concentrated lime solutions. J Colloid Interface Sci 339:103-109

Langmuir I (1916) The constitution and fundamental properties of solids and liquids. J Am Chem Soc 38:2221-2295

Lian F, Sun B, Song Z, Zhu L, Qi X, Xing B (2014) Physicochemical properties of herb-residue biochar and its sorption to ionizable antibiotic sulfamethoxazole. Chem Eng J 248:128-134

Ma Y, Li M, Wu M, Li Z, Liu X (2015) Occurrences and regional distributions of 20 antibiotics in water bodies during groundwater recharge. Sci Total Environ 518-519:498-506

Mahmoud HR, Ibrahim SM, El-Molla SA (2016) Textile dye removal from aqueous solutions using cheap $\mathrm{MgO}$ nanomaterials: adsorption kinetics, isotherm studies and thermodynamics. Advanced Powder Technol 27:223-231

Mehta D, Mazumdar S, Singh SK (2015) Magnetic adsorbents for the treatment of water/wastewater-a review. J Water Proc Eng $7: 244-265$
Nagy B, Carmen M, Andrada M, Cerasella I, Barbu-Tudoran L, Cornelia M (2017) Linear and nonlinear regression analysis for heavy metals removal using agaricus bisporus macrofungus. Arab J Chem 10:S3569-S3579

Namduri H, Nasrazadani S (2008) Quantitative analysis of iron oxides using Fourier transform infrared spectrophotometry. Corr Sci 50:2493-2497

Ngumba E, Gachanja A, Tuhkanen T (2016) Occurrence of selected antibiotics and antiretroviral drugs in Nairobi river basin. Sci Total Environ 539:206-213

Primel E, Caldas S, Escarrone A (2012) Multi-residue analytical methods for the determination of pesticides and PPCPs in water by LC-MS/MS: a review. Open Chem 10:876-899

Saleh TA (2015) Isotherm, kinetic, and thermodynamics studies on $\mathrm{Hg}(\mathrm{II})$ adsorption from aqueous solution by silica-multiwall carbon nanotubes. Environ Sci Pollut Res 22:16721-16731

Salem TM, Hu XL, Yin DQ (2013) Synthesized magnetic nanoparticles coated zeolite for the adsorption of pharmaceutical compounds from aqueous solution using batch and column studies. Chemosphere 93:2076-2085

Shahmohammadi-Kalalagh S, Babazadeh H, Nazemi AH, Manshouri $\mathrm{M}$ (2011) Isotherm and kinetic studies on adsorption of $\mathrm{Pb}, \mathrm{Zn}$ and $\mathrm{Cu}$ by Kaolinite, Caspian. J Env Sci 9:243-255

Shikuku VO, Donato FF, Kowenje CO, Zanella R, Prestes DO (2015) A comparison of adsorption equilibrium, kinetics and thermodynamics of aqueous phase clomazone between faujasite $\mathrm{x}$ and a natural zeolite from Kenya. S Afr J Chem 68:245-252

Shikuku VO, Zanella R, Kowenje CO, Donato FF, Bandeira N, Prestes DO (2017) Single and competitive removal of sulfachloropyridazine and sulfadimethoxine onto natural kaolinite clay: kinetics, isotherms and thermodynamics studies. S Afr J Chem 70:120-126

Teixidó M, Pignatello JJ, Beltrán JL, Granados M, Peccia J (2011) Speciation of the ionizable antibiotic sulfamethazine on black carbon (biochar). Environ Sci Technol 45:10020-10027

Temkin MI (1941) Adsorption equilibrium and the kinetics of processes on non-homogeneous surfaces and in the interaction between adsorbed molecules. Zh. Fiz. Chim. 15:296-332

Tireli AA, Francielle CF, Laís FO, Iara RG, Mário CG, Joaquim PS (2014) Influence of magnetic field on the adsorption of organic compound by clays modified with iron. Appl Clay Sci 97-98:1-7

Treybal, R.E., 1981. Mass-transfer Operations, 3rd ed., McGraw-Hill. using tree fern as a biosorbent. Process Biochemistry, 40 (1), $119-124$

Weber WJ, Morris JC (1963) "Kinetics of Adsorption on Carbon from Solution”. J. San. Eng.: Am. Soc. Civ. Eng. 89:31-59

Zhang Q, Jia A, Wan Y, Hu J (2014) Occurrences of Three Classes of Antibiotics in a Natural River Basin: association with AntibioticResistant Escherichia coli. Environ Sci Technol 48:14317-14325

Zhao F, Zhang B, Feng L (2012) Preparation and magnetic properties of magnetite nanoparticles. Mater Lett 68:112-114

Publisher's Note Springer Nature remains neutral with regard to jurisdictional claims in published maps and institutional affiliations. 